\title{
DEFICIÊNCIAS FUNCIONAIS E INSUFICIÊNCIAS ESTRUTURAIS EM OAES: ESTUDO DE CASO
}

\author{
PEREIRA, RODRIGO \\ Engenheiro Civil \\ Strata Engenharia Ltda. \\ Minas Gerais; Brasil \\ rodrigoestruturas@gmail.com \\ MARTINS, VITOR ARAÚJO \\ Engenheiro Civil \\ Strata Engenharia Ltda. \\ Minas Gerais; Brasil \\ vitoraraujomartins@outlook.com
}

\author{
DO CARMO, ANNE KARONLINE FORTUNATO \\ Engenheira Civil \\ Pontifícia Universidade Católica de Minas Gerais \\ Minas Gerais; Brasil \\ annekarolinefc@gmail.com
}

\author{
DE ALENCAR, CECÍLIA NARDI \\ Estudante \\ Universidade Federal de Minas Gerais \\ Minas Gerais; Brasil \\ cecilia.nardi@hotmail.com
}

\section{RESUMO}

As Obras de Arte Especiais são estruturas que estão sujeitas a constantes ataques e deteriorações externas, sejam eles ocasionados por agentes atmosféricos, ação dos usuários ou pela ausência de manutenção e conserva das obras. Com isso, há o surgimento de patologias e desgastes, sendo necessária a prevenção para que a segurança dos usuários seja mantida. O referente trabalho tem como objetivo apresentar as patologias presentes em duas OAEs localizadas no Estado de Alagoas, abordando as deficiências funcionais e as insuficiências estruturais identificadas por meio de Inspeção Cadastral e Rotineira.

Palavras-chave: Estruturas, deficiências funcionais, insuficiências estruturais, inspeção.

\section{ABSTRACT}

The OAEs are structures that are subject to constant attacks and external deterioration, whether caused by atmospheric agents, user action or the lack of maintenance and preservation. With the emergence of pathologies and wear, prevention is required to maintain user safety. This paper aims to present the pathologies in 2 (two) OAEs located in the State of Alagoas, addressing functional deficiencies and structural insufficiencies through Cadastral and Routine Inspection.

Keywords: Structures, functional disabilities, structural insufficiencies, inspection.

\section{INTRODUÇÃO}

As Obras de Artes Especiais (OAEs) podem apresentar deficiências funcionais ou estruturais. São consideradas funcionalmente deficientes quando aspectos do projeto não estão apropriados para o tipo de tráfego local ou quando não possuírem requisitos geométricos adequados. De acordo com o DNIT (2013), são exemplos de deficiências funcionais: pontes estreitas, ponte sem acostamento, pingadeira inexistente, drenagem da pista insuficiente, presença de junta longitudinal de dilatação, viga caixão com interior inacessível, guarda rodas obsolto, dentre outros. Por sua vez, pontes e viadutos podem tornar-se estruturalmente insuficientes, casos sujeitos a corrosão, deterioração do concreto, fissuras, excesso de cargas, vibrações e deformações, associadas a condições ambientais e umidade, comprometendo a estabilidade e capacidade portante da obra.

A deteterioração elevada das obras de arte pode ser agravada pela ausência de manutenção e conserva, bem como pela falta de inspeções periódicas. O conceito de manutenção implica que pequenos reparos e serviços sejam realizados de forma a manter a estrutura em ótimas condições de funcionamento. Nesse sentido, o Manual de Inspeção de Pontes Rodoviárias (2004) prevê cinco tipos de inspeções: Inspeção Cadastral, Inspeção Rotineira, Inspeção Especial, Inspeção Extraordinária e Intermediária. Este artigo tratará de Inspeções Cadastrais, ou seja, aquelas que devem ser feita após a conclusão ou alteração da configuração da obra, e Inspeções Rotineiras, programada com intervalos adequados e destinada a coletar anomalias e informações pertinentes, de obras de artes localizadas no Estado de Alagoas. 
O Estado de Alagoas abrange 261 pontes e viadutos em rodovias estaduais. O trabalho teve como objetivo averiguar as manifestações patológicas, condições estruturais e a funcionalidade de duas obras do Estado, bem como realizar análises comparativas entre os níveis de deterioração destas OAEs.

\section{DESENVOLVIMENTO}

O estudo de caso consistiu em verificar as deficiências estruturais e a funcionalidade de duas obras de arte especiais, tendo como referência Inspeções Cadastais e Rotineiras realizadas. Tais informações foram fundamentais para análise e comparação das manifestações patológicas e das condições apresentadas pelas duas obras em estudo. As principais patologias diagnosticadas nas pontes em análise foram corrosão na armadura, desagregação no concreto, degradação devido à ação biológica, infiltração no concreto, nichos de concretagem, lixiviação e mancha de carbonatação, erosão no talude e armadura sem cobrimento. Tais manifestações patológicas, bem como as deficiências funcionais apresentadas pelas pontes, serão expostas e exemplificadas no estudo de caso a seguir.

Vale ressaltar que as notas de estabilidade e conservação das obras foram determinadas mediante as inspeções realizadas, levando em conta as manifestações patológicas, insuficiências estruturais e deficiências funcionais apresentadas pelos elementos. Como referenciador destas análises, foi utilizada a nova versão da NBR 9452 (ABNT, 2016), que, por meio de parâmetros estruturais, funcionais e de durabilidade, classificam as estruturas e metodologias da Norma DNIT 010/2004 - PRO, a qual fundamenta a condição de estabilidade da estrutura para indicação da nota de classificação, destacadas, respectivamente, nas Tabelas 1 e 2 a seguir.

Tabela 1 - Classificação da condição de OAEs segundo os parâmetros estrutural, funcional e de durabilidade NBR 9452 (ABNT, 2016).

\begin{tabular}{|c|c|c|c|c|}
\hline Nota & Condição & Caracterização Estrutural & Caracterização funcional & $\begin{array}{c}\text { Caracterização de } \\
\text { durabilidade }\end{array}$ \\
\hline 5 & Excelente & $\begin{array}{lrr}\text { A estrutura } & \text { apresenta-se em } \\
\text { condições } & \text { satisfatórias, com } \\
\text { defeitos } & \text { irrelevantes } & \text { e } \\
\text { isolados. } & & \end{array}$ & $\begin{array}{l}\text { A OAE apresenta segurança } \\
\text { e conforto aos usuários. }\end{array}$ & $\begin{array}{l}\text { A OAE apresenta-se em } \\
\text { perfeitas condições devendo } \\
\text { ser prevista manutenção de } \\
\text { rotina. }\end{array}$ \\
\hline 4 & Boa & $\begin{array}{l}\text { A estrutura apresenta danos } \\
\text { pequenos e em áreas, sem } \\
\text { comprometer a segurança } \\
\text { estrutural. }\end{array}$ & $\begin{array}{l}\text { A OAE apresenta pequenos } \\
\text { danos que não chegam a } \\
\text { causar desconforto ou } \\
\text { insegurança ao usuário. }\end{array}$ & $\begin{array}{l}\text { A OAE apresenta poucas } \\
\text { anomalias, que comprometem } \\
\text { sua vida útil, em região de } \\
\text { baixa agressividade ambiental. }\end{array}$ \\
\hline 3 & Regular & $\begin{array}{l}\text { Há danos que podem gerar } \\
\text { deficiência estrutural. Não há } \\
\text { sinais de comprometimento da } \\
\text { estabilidade da obra. } \\
\text { Recomenda-se acompanhar os } \\
\text { problemas. Intervenções } \\
\text { podem ser necessárias em } \\
\text { médio prazo. }\end{array}$ & $\begin{array}{l}\text { A OAE apresenta } \\
\text { desconforto ao usuário, com } \\
\text { defeitos que requerem ações } \\
\text { de médio prazo. }\end{array}$ & $\begin{array}{l}\text { OAE apresenta pequenas e } \\
\text { poucas anomalias que } \\
\text { comprometem a sua vida útil, } \\
\text { em região de moderada à alta } \\
\text { agressividade ambiental; a } \\
\text { OAE apresenta moderadas a } \\
\text { muitas anomalias, que } \\
\text { comprometem sua vida útil, } \\
\text { em região de baixa } \\
\text { agressividade ambiental. }\end{array}$ \\
\hline 2 & Ruim & $\begin{array}{l}\text { Há danos que comprometem a } \\
\text { segurança estrutural da OAE, } \\
\text { sem risco iminente. Sua } \\
\text { evolução pode levar ao } \\
\text { colapso estrutural. Necessita } \\
\text { de intervenções a curto prazo. }\end{array}$ & $\begin{array}{l}\text { OAE com funcionalidade } \\
\text { visivelmente comprometida, } \\
\text { com riscos de segurança ao } \\
\text { usuário, requerendo } \\
\text { intervenções de curto prazo. }\end{array}$ & $\begin{array}{lr}\text { A OAE apresenta moderadas a } \\
\text { muitas } & \text { manifestações } \\
\text { patológicas, } & \text { que } \\
\text { comprometem sua vida útil, } \\
\text { em região de alta } \\
\text { agressividade ambiental. }\end{array}$ \\
\hline 1 & Crítica & $\begin{array}{l}\text { Há danos que geram grave } \\
\text { insuficiência estrutural e } \\
\text { elementos estruturais em } \\
\text { estado crítico e risco tangível } \\
\text { de colapso estrutural. } \\
\text { Necessita de intervenção } \\
\text { imediata. }\end{array}$ & $\begin{array}{ll}\text { A OAE } & \text { não apresenta } \\
\text { condições } & \text { funcionais de } \\
\text { utilização. } & \end{array}$ & $\begin{array}{l}\text { A OAE encontra-se em } \\
\text { elevado grau de deterioração, } \\
\text { apontando problema já de } \\
\text { risco estrutural e/ou funcional. }\end{array}$ \\
\hline
\end{tabular}


Tabela 2-Relação entre as notas atribuídas e problemas estruturais observados em inspeção (DNIT 010/2004 PRO).

\begin{tabular}{|c|c|c|c|c|}
\hline Nota & $\begin{array}{c}\text { Danos no eleento/insuficiência } \\
\text { estrutural }\end{array}$ & Ação Corretiva & $\begin{array}{l}\text { Condição de } \\
\text { estabilidade }\end{array}$ & $\begin{array}{l}\text { Classificação } \\
\text { da OAE }\end{array}$ \\
\hline 5 & $\begin{array}{l}\text { Não há danos nem insuficiência } \\
\text { estrutural. }\end{array}$ & Nada a fazer. & Boa & $\begin{array}{l}\text { Obra sem } \\
\text { problemas }\end{array}$ \\
\hline 4 & $\begin{array}{l}\text { Há alguns danos, mas não há } \\
\text { sinais de que estejam gerando } \\
\text { insuficiência estrutural. }\end{array}$ & $\begin{array}{l}\text { Nada a fazer; apenas serviços } \\
\text { de manutenção. }\end{array}$ & Boa & $\begin{array}{l}\text { Obras sem } \\
\text { problemas } \\
\text { sérios }\end{array}$ \\
\hline 3 & $\begin{array}{l}\text { Há alguns danos gerando } \\
\text { insuficiência estrutural, mas não } \\
\text { há sinais de comprometimento da } \\
\text { estabilidade da obra. }\end{array}$ & $\begin{array}{l}\text { A recuperação da obra pode ser } \\
\text { postergada, devendo-se, porém, } \\
\text { colocar-o problema em observação } \\
\text { sistemática. }\end{array}$ & $\begin{array}{c}\text { Boa ou boa } \\
\text { aparentemente }\end{array}$ & $\begin{array}{l}\text { Obra } \\
\text { potencialmente } \\
\text { problemática }\end{array}$ \\
\hline 2 & $\begin{array}{l}\text { Há alguns danos gerando } \\
\text { insuficiência estrutural, mas não } \\
\text { há sinais de comprometimento da } \\
\text { estabilidade da obra. }\end{array}$ & $\begin{array}{l}\text { A recuperação (geralmente com } \\
\text { reforço estrutural) da obra deve ser } \\
\text { feita em curto prazo. }\end{array}$ & Sofrível & $\begin{array}{l}\text { Obra } \\
\text { problemática }\end{array}$ \\
\hline 1 & $\begin{array}{l}\text { Há danos gerando grave } \\
\text { insuficiência estrutural da ponte; } \\
\text { o elemento em questão encontra- } \\
\text { se em estado crítico, com risco } \\
\text { tangível de colapso estrutural. }\end{array}$ & $\begin{array}{l}\text { A recuperação (geralmente reforço } \\
\text { estrutural), ou em alguns casos, } \\
\text { substituição da obra deve ser feita } \\
\text { sem tardar. }\end{array}$ & Precária & Obra crítica \\
\hline
\end{tabular}

\section{ESTUDO DE CASO}

\subsection{Obras analisadas}

A Tabela 3 a seguir apresenta a identificação, localização e porte das duas obras de artes analisadas.

\begin{tabular}{c|c|c}
\hline Identificação da OAE & Ponte Sobre o Riacho Camandatuba & Ponte sobre o Riacho Grande \\
\hline Rodovia & $\mathrm{AL}-101$ & $\mathrm{AL}-115$ \\
Coordenadas (Latitude/Longitude) & $9^{\circ} 4.010^{\prime} \mathrm{S} / 35^{\circ} 14.529{ }^{\prime} \mathrm{O}$ & $10^{\circ} 0.555^{\prime} \mathrm{S} / 36^{\circ} 47.644{ }^{\prime} \mathrm{O}$ \\
Município & $\mathrm{Japaratinga}^{\circ}$ & $\mathrm{Campo} \mathrm{Grande}$ \\
Extensão (m) & 6000 & 36,00 \\
Largura (m) & 10,00 & 9,60 \\
\hline
\end{tabular}

3.1.1 Manifestações patológicas identificadas nas obras em análise

Segundo SILVA (2010), a patologia é uma ciência formada por um conjunto de teorias que serve para explicar o mecanismo e a causa da ocorrência de determinada manifestação patológica, e esta última é a expressão resultante de um mecanismo de degradação. Serão apresentadas a seguir as manifestações patológicas identificadas por meio de Inspeções Cadastrais e Rotineiras nas duas obras de arte especiais analisadas.

\section{- Ponte sobre o Riacho Camandatuba}

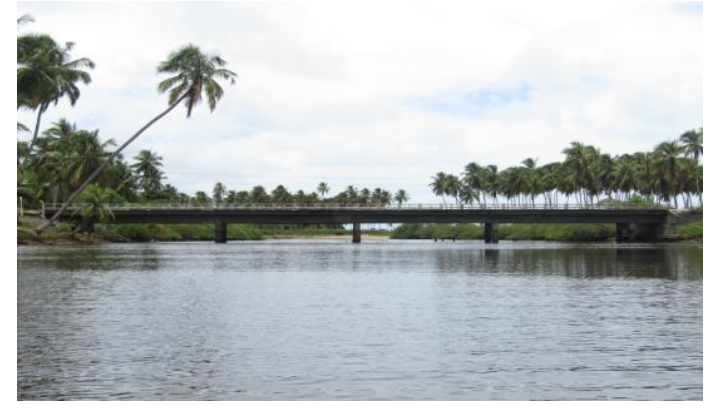

Figura 1: Vista longitudinal da OAE.

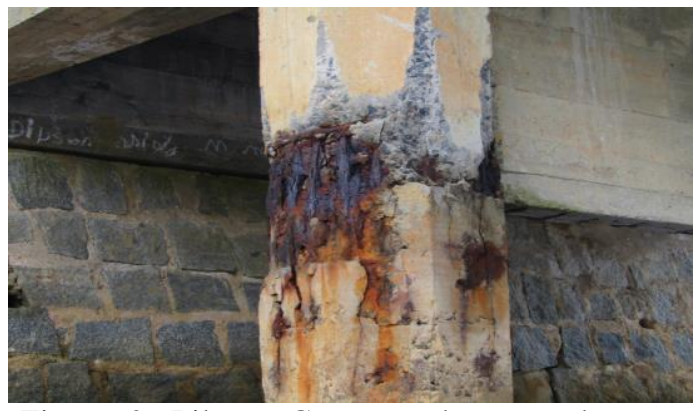

Figura 2: Pilar - Concreto desagregado com armadura exposta e oxidada. 


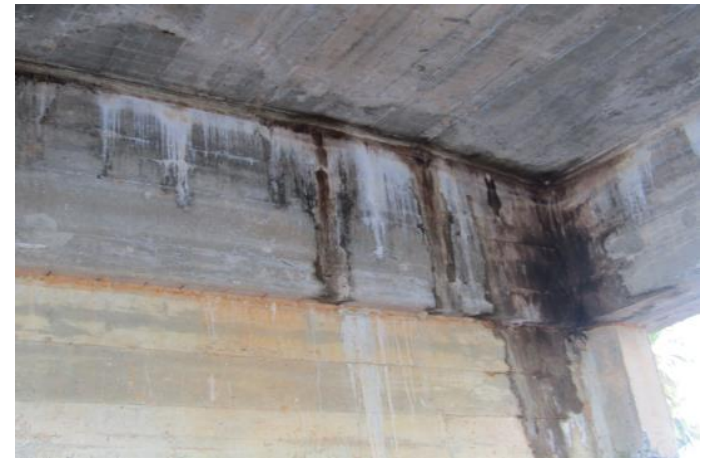

Figura 3: Transversina, viga e laje Degradação no concreto devido ação biológica.

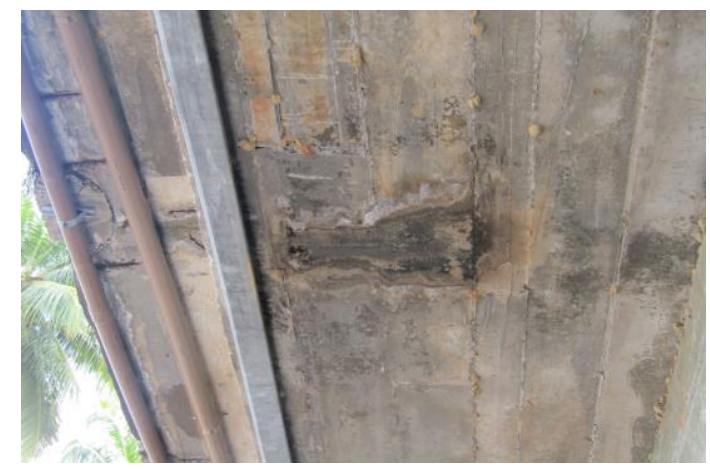

Figura 5: Laje - Infiltração no concreto e concreto desagregado com armadura exposta.

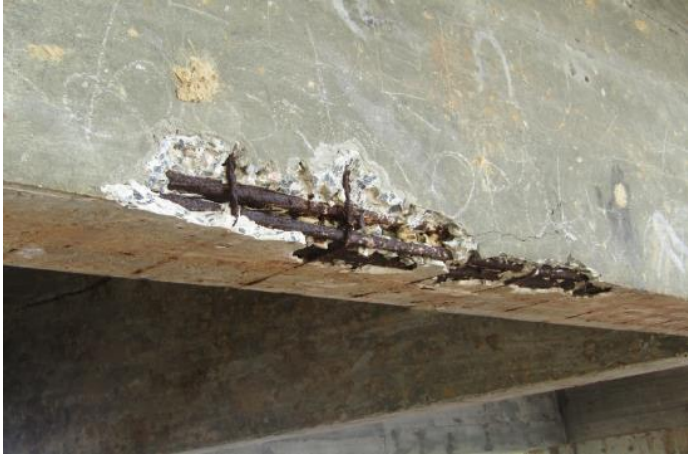

Figura 4: Viga - Desplacamento de concreto com armadura exposta e armadura sem cobrimento.

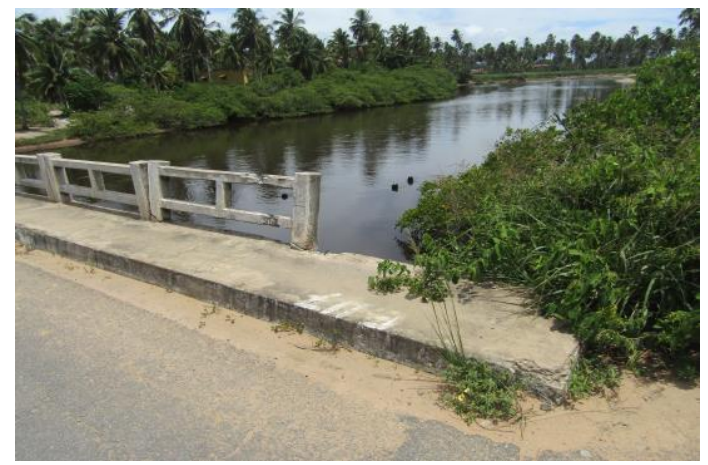

Figura 6: Guarda corpo destruído.

Dentre as manifestações patológicas apresentadas por esta OAE, as mais alarmantes ocorrem nos pilares (Figura 2), que possuem um grau avançado de oxidação das armaduras, devido à próximidade da obra a região litorânea e meio ambiente agressivo. Como mencionado, tal manifestação reduz a capacidade mecânica e a seção da armadura, podendo ocasionar ruína ou colapso da estrutura. Verifica-se, também, pela Figura 5 que a laje em balanço apresenta drenos danificados, provocando infiltração de águas pluviais, lixiviação e desagregação do concreto. Outra manifestação patológica verificada na ponte é a mancha de guano, em decorrência de excrementos de morcegos, apresentada na Figura 3. Nota-se que apesar das vigas, lajes e transvesinas apresentarem o dano, a degradação dos elementos ainda não atingiu um nível de deterioração considerável, caracterizado pela desagregação do concreto e exposição das armaduras. Já o desplacamento de concreto com armadura exposta, verificado na Figura 4, pode ter ocorrido devido a choques, corrosão da armadura, pressão ou expensão no interior do concreto. Por último, o dispositivo de segurança da OAE, além de ser obsoleto, também está destruído, conforme identificado na Figura 6. Sendo assim, pode-se dizer que as condições de estabilidade e conservação da ponte encontram-se precárias e a obra necessita de intervenções imediatas.

\section{- $\quad$ Ponte sobre Riacho Grande}

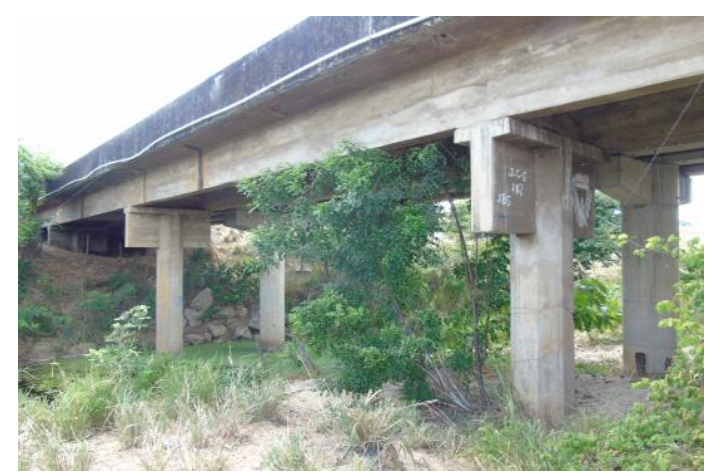

Figura 7: Vista longitudinal da OAE.

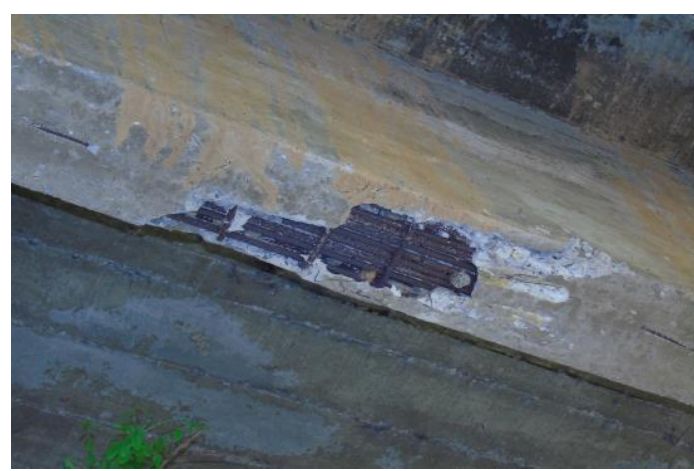

Figura 8: Viga - Nicho de concretagem e armadura sem cobrimento. 


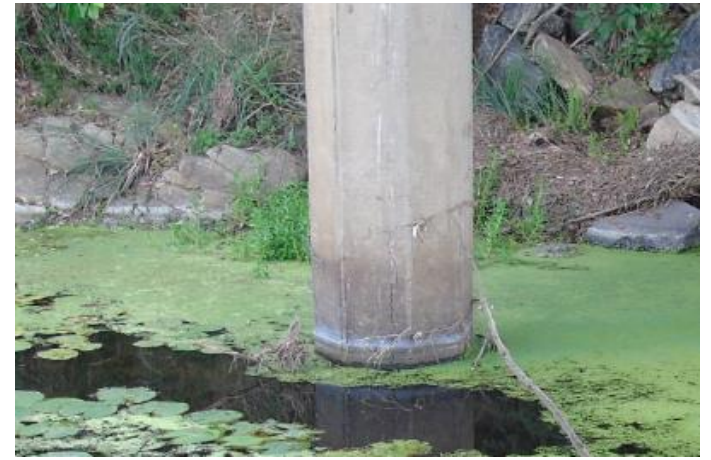

Figura 9: Pilar - Fissura profunda fina e infiltração no concreto.

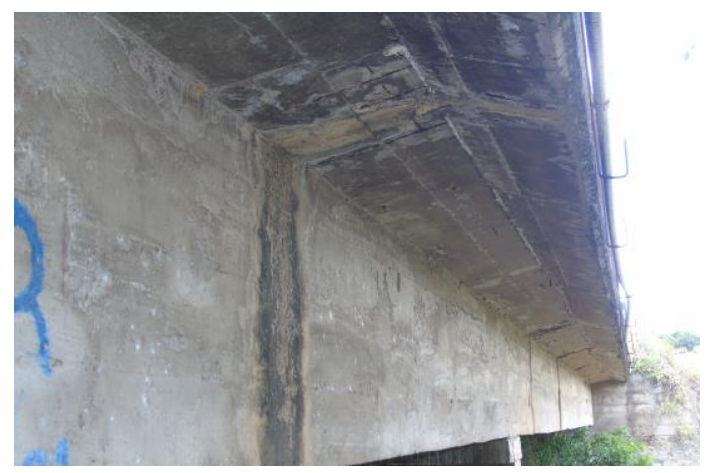

Figura 11: Laje - Infiltração no concreto, lixiviação e concreto desagregado com armadura exposta.

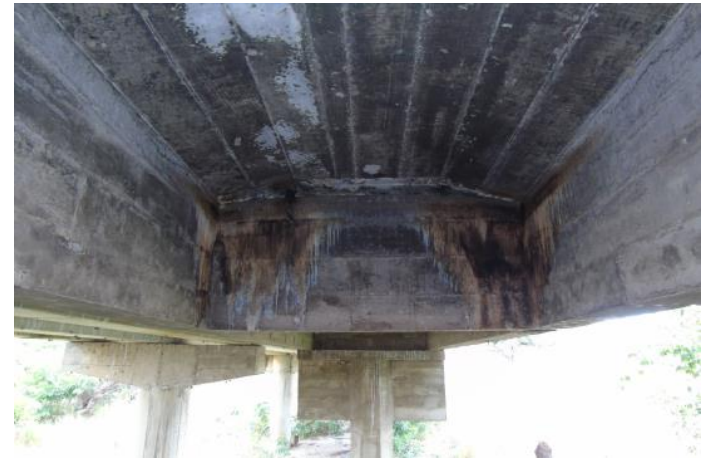

Figura 10: Travessa, Viga, Pilar e Transversina Degradação no concreto devido ação biológica.

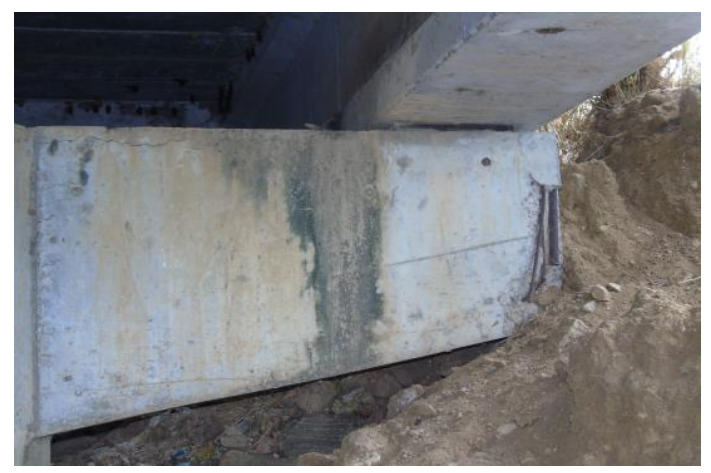

Figura 12: Erosão no talude de aterro e concreto desagregado com armadura exposta no encontro.

As manifestações patológicas apresentadas por esta OAE são menos agressivas quando comparadas as da Ponte sobre $o$ Riacho Camandatuba, o que justifica as melhores condições de estabilidade e conservação da obra. É verificado que as vigas da estrutura apresentam pontos com nichos de concretagem (Figura 8), em decorrência de deficiências advindas do processo de concretagem, o que torna as armaduras do elemento mais sucetíveis à corrosão. Observa-se, também, pela Figura 9, uma fissura profunda fina no pilar, ou seja, com abertura menor que 0,3 mm, porém dentro dos limites permitidos pela NBR 6118 (2007). Pode-se imaginar que esta fissura surgiu a partir da umidade do local e confere vulnerabilidade a estrutura, possibilitando a entrada de agentes corrosivos. Assim como na Ponte sobre o Riacho Camandatuba, as manchas de guano nas vigas, transversinas e lajes (Figura 10) apresentam-se em grande quantidade, no entanto, a deteterioração do concreto ainda não atingiu um nível elevado, definido pela desagregação do concreto e exposição das armaduras. A infiltração do concreto e a lixiviação na laje em balanço ocorrem em razão da percolação de água no elemento devido à ineficiência da pingadeira, deteriorando o concreto e expondo as armaduras, conforme verificado na Figura 11. Por último, a erosão no talude de aterro, identificada na Figura 12, é consequência de um sistema de drenagem ineficiente da obra, ou ausência de laje de transição, responsável por conter movimentações no aterro de acesso. Pode-se dizer, portanto, que as condições de estabilidade e conservação da ponte encontram-se regulares, no entanto, a obra pode necessitar de intervenções em médio prazo.

\subsubsection{Deficiências funcionais}

A NBR 9452:2016 estabelece como parâmetros funcionais os aspectos das OAEs diretamente ligados aos seus fins de utilização e que visam garantir conforto e segurança a seus usuários. Foram identificadas deficiências funcionais para ambas as obras analisadas e relacionadas na Tabela 4 a seguir.

Tabela 4 - Deficiências funcionais nas obras em análise.

\begin{tabular}{c|c}
\hline Ponte sobre o Riacho Camandatuba & Ponte sobre o Riacho Grande \\
\hline Ponte sem acostamento & Ponte sem acostamento \\
Ausência de dispositivos de segurança & Ausência de dispositivos de segurança \\
Pingadeira inexsitente/Sistema de drenagem ineficiente & Pingadeira inexsitente/Sistema de drenagem ineficiente \\
Trem tipo de cálculo TB 36tf & Trem tipo de cálculo TB 24 tf \\
Pilar em canal de navegação sem proteção & Junta longitudinal de dilatação \\
\hline
\end{tabular}


De acordo com o Manual de Projeto Geométrico de Rodovias Rurais (1999), as OAEs devem sempre apresentar faixas de acostamento com a mesma largura do trecho que a compõem, de forma a possibilitar uma área segura para desvio de veículos em situações de risco, manobras perigosas ou quando apresentarem problemas. Nota-se que, em ambas as pontes, inexistem faixas de acostamento, comprometendo a segurança dos usuários da via, conforme Figuras 13 e 14.

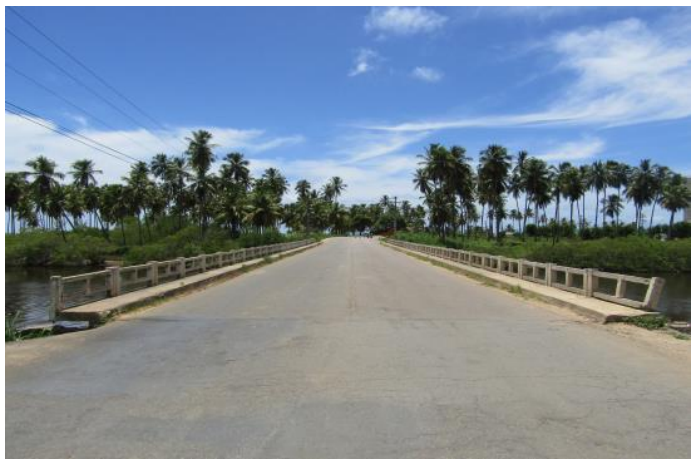

Figura 13: Ponte sobre o Riacho Camandatuba - Ponte sem acostamento e guarda corpo obsoleto.

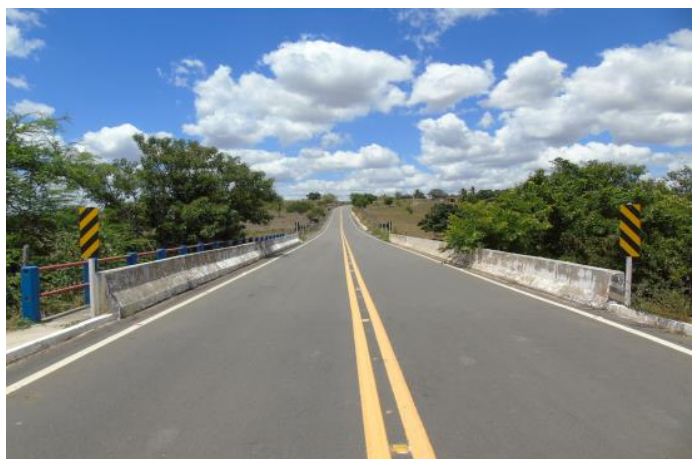

Figura 14: Ponte sobre o Riacho Grande Ponte se acostamento.

Assim como as faixas de acostamento, guarda corpos, barreiras de concreto e defensas metálicas são essencias para garantir a segurança viária. Atualmente, em pontes de construção mais recente, os guarda-corpos somente existem se houverem passeios laterais, no intuito de assegurar proteção a pedestres e ciclistas, como é o caso da Ponte sobre o Riacho Grande (Figura 14), em que a proteção lateral contra choque de veículos é feita pela barreira New Jersey. A barreira New Jersey em uma colisão consegue absorver melhor a energia cinética do veículo, redirecionando o mesmo para a faixa de tráfego e, por isso, é internacionalmente aceita. Já a Ponte sobre o Riacho Camandatuba, além de possuir um dispositivo obsoleto de segurança lateral, o mesmo ainda se encontra destruído, conforme Figura 6. Ademais, ambas as pontes não apresentam defensas metálicas. Pode-se dizer, portanto que tanto a Ponte sobre o Riacho Camandatuba e a Ponte sobre o Riacho Grande possuem deficiências funcionais associadas à instalação inadequada de dispositivos de segurança.

Outra deficiência funcional constatada em ambas as pontes é a ausência de pingadeira e dipositivos de drenagem danificados ou obstruídos. A Ponte sobre o Riacho Grande apresenta pingadeira apenas do lado direito, conforme Figura 15. Ainda assim, águas pluviais infiltram na laje em balanço, causando deterioração do concreto e exposição das armaduras, o que indica ineficiência da pingadeira existente. Além disso, na Figura 15, também é identificado um buzinote danificado. Este elemento, que teria a função de contribuir com a drenagem da estrutura, quando danificado, acaba por permitir a infiltração de água no concreto. Já do lado esquerdo da obra, onde inexiste pingadeira, também ocorre infiltração na laje em balanço, conforme Figura 16.

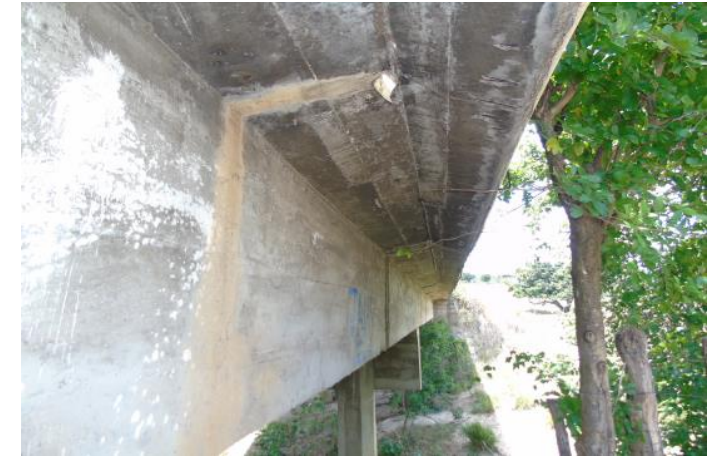

Figura 15: Ponte sobre o Riacho Grande - Lado direito - Pingadeira ineficiente e buzinote danificado.

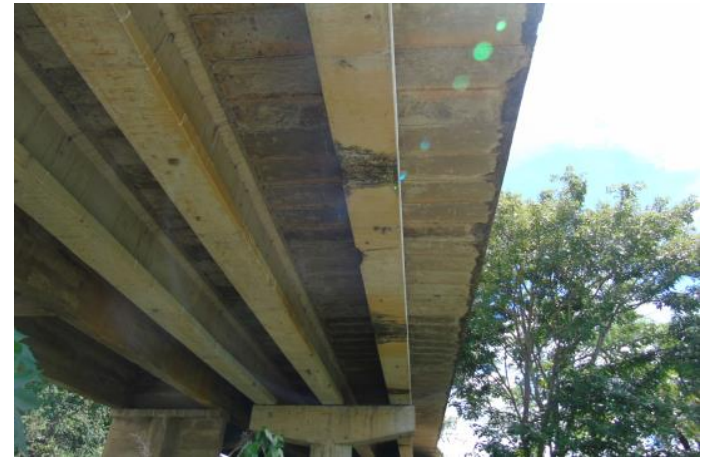

Figura 16: Ponte sobre o Riacho Grande - Lado esquerdo - Pingadeira inexistente.

A Ponte sobre o Riacho Camandatuba apresenta a mesma deficiência. Pode-se observar pela Figura 17 que a inexistência da pingadeira ocasionou infiltração na laje e lixiviação, desagregando o concreto e expondo as armaduras 
aos agentes corrosivos. Além disso, todos os buzinotes instalados ao longo da laje se encontram danificados, conforme Figuras 17 e 18.

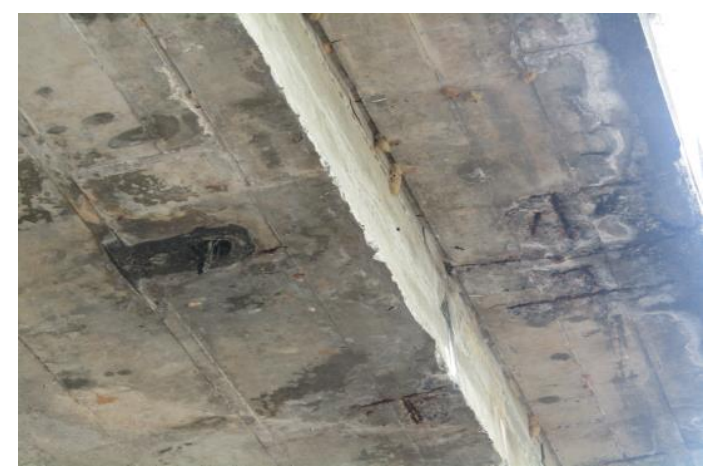

Figura 17: Ponte sobre o Riacho Camandatuba - Pingadeira inexistente e buzinote danificado.

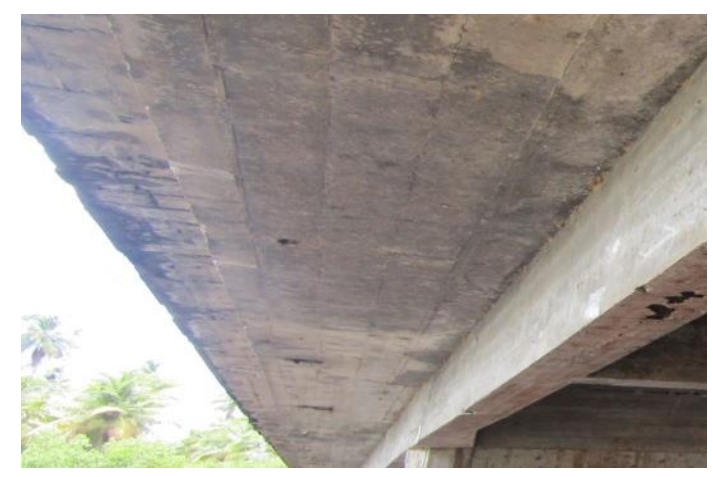

Figura 18: Ponte sobre o Riacho Camandatuba - Buzinotes danificados.

Por meio de levantamento de campo foram coletadas informações como registros fotográficos, medidas para detalhamento da geometria com as dimensões das obras e identificação das deficiências funcionais. Estima-se que a Ponte sobre o Riacho Grande é de antes de 1960, porém foi construída uma nova estrutura ao seu lado para atender a capacidade de tráfego da via, apresentando atualmente 9,60 m de seção transversal e barreira New Jersey, conforme Figura 18. A parte considerada como a mais antiga, possui duas vigas concretadas junto à laje, sistema estrutural moldado in loco, apresenta características de obras construídas entre 1950 a 1960 e dimensionamento para Trem Tipo Classe 24 tf. Já a segunda parte "nova" da estrutura, constituída por três vigas "I", possui características de obras construídas após 1985 com Trem Tipo Classe 45 tf, conforme o Manual de Inspeções IPR-709/2004, do DNIT. Por outro lado, estima-se que a Ponte sobre o Riacho Camandatuba, com 10,00 m de seção transversal e guarda corpo com $90 \mathrm{~cm}$ de altura, foi construída entre 1960 e 1975 e calculada para Trem Tipo Classe 36 tf, como mostra a Figura 19. Como as estruturas atuais são calculadas utilizando-se o Trem Tipo Classe $45 \mathrm{tf}$, pode-se dizer que ambas as obras apresentam deficiências funcionais devido à época em que foram dimensionadas e construídas.

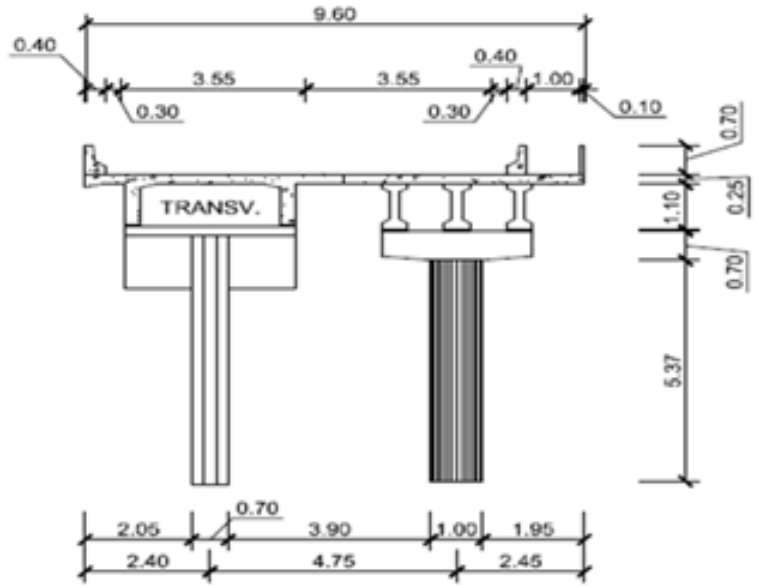

Figura 18: Seção transversal - Ponte sobre o Riacho Grande.

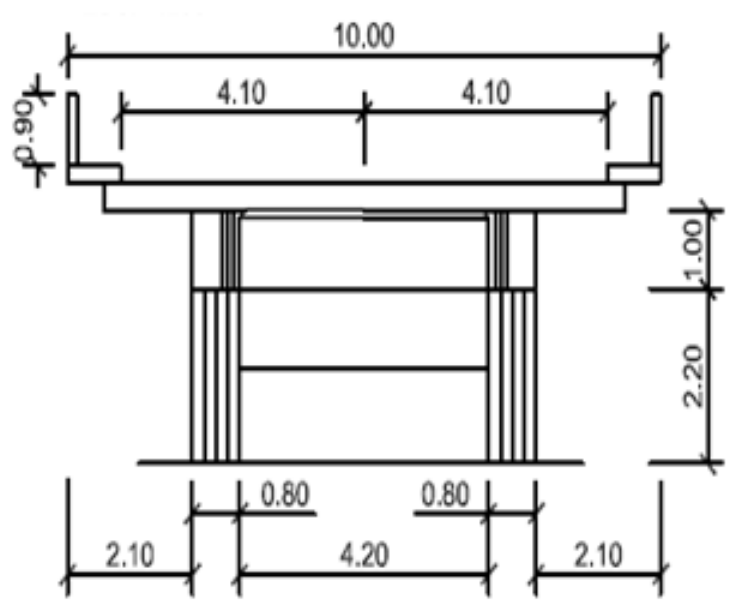

Figura 19: Seção transversal - Ponte sobre o Riacho Camandatuba.

Nas Figuras 20 e 21 podem-se identificar manifestações patológicas como lixiviação e mancha de carbonatação, infiltração e desagregação do concreto da laje, devido à existência de uma junta longitudinal de dilatação na Ponte sobre o Riacho Grande. Não é possível verificar nenhuma estanqueidade para evitar a percolação de água na laje e nas vigas de concreto armado, sendo assim, necessário eliminar a junta em questão a fim de garantir a funcionalidade da estrutura. 


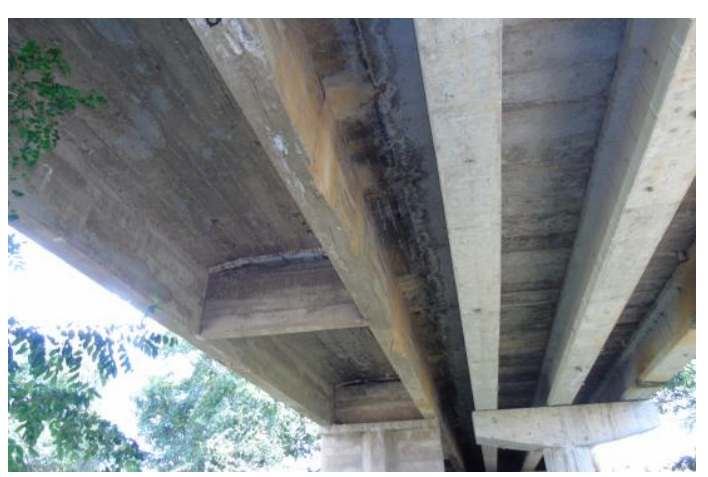

Figura 20: Ponte sobre o Riacho Grande Manifestações patológicas devido à junta longitudinal.

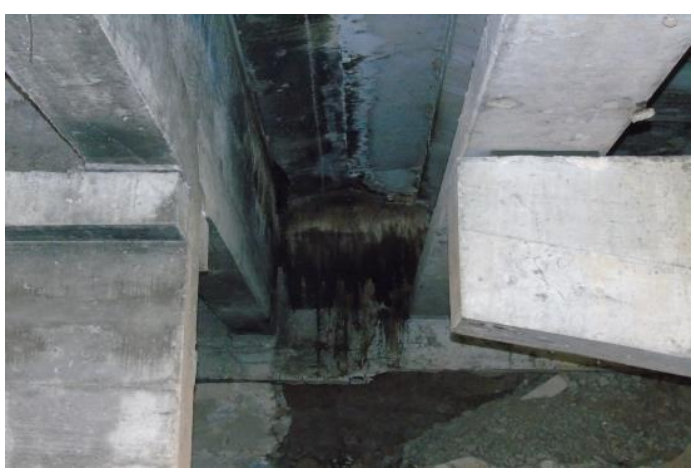

Figura 21: Ponte sobre o Riacho Grande Manifestações patológicas devido à junta longitudinal.

Por fim, conforme Figura 1 anteriormente exposta, nota-se a inexistência de dispositivos de proteção nos pilares da estrutura da Ponte sobre o Riacho Camandatuba, localizada em um canal de navegação. Para garantir a segurança funcional e estrutural da OAE em questão, evitando eventuais colisões nos elementos da mesoestrutura, é indicada a instalação de dolfins nos pilares dos vãos navegáveis. Segundo SILVA (2016), dolfins são definidos como elementos de proteção contra colisão de embarcações e funcionam principalmente como obstáculos de gravidade. Esse sistema é constituído por uma estrutura de forma circular, com estacas tipo pranchas metálicas, formando o perímetro, cravadas no solo até determinada profundidade e com o interior preenchido com material granular, sendo solidarizados por uma laje rígida de concreto armado.

\subsubsection{Insuficiências estruturais}

As manifestações patológicas e as deficiências funcionais das estruturas em análise podem significar sério comprometimento da vida útil da OAE. Para as obras em análise, estas manifestações presentes estão diretamente relacionadas às insuficiências estruturais apresentadas. A Ponte sobre o Riacho Camandatuba, em seu estado atual, apresenta patologias e deficiências que requerem serviços de manutenção imediatos, principalmente no que diz respeito à recuperação dos pilares e vigas da estrutura, que se encontram com armaduras de protensão expostas e deterioradas, conforme anteriormente exposto pelas Figuras 2 e 4 . A recuperação destes elementos é imprescindível para garantir melhores condições de estabilidade estrutural da OAE. Já a Ponte sobre o Riacho Grande não apresenta sinais de comprometimento de sua estabilidade, mas ainda assim, as vigas da estrutura possuem insuficiências estruturais, que devem ser acompanhadas. Intervenções neste elemento podem ser necessárias em médio prazo, uma vez observada sua deterioração acentuada e condições atuais, conforme Figura 8.

\subsubsection{Condições de Estabilidade e conservação}

A partir das inspeções realizadas na Ponte sobre o Riacho Camandatuba e Ponte sobre o Riacho Grande, foi possível verificar as manifestações patológicas, deficiências funcionais, e insuficiências estruturais da obra. Constatou-se que, tanto em termos de funcionalidade, conservação e estabilidade estrutural, a Ponte sobre o Riacho Grande apresenta melhores condições que a Ponte sobre o Riacho Camandatuba. Sendo assim, pode-se afirmar que a primeira encontrase em condições regulares, podendo necessitar de intervenções em médio prazo. Já a última, necessita de intervenções imediatas e encontra-se em uma situação precária.

Dessa forma e, com base no que foi exposto nas Tabelas 1 e 2, as pontes foram avaliadas com notas de estabilidade e estrutural conforme Tabela 5.

Tabela 5 - Condições estabilidade e conservação das OAE's

\begin{tabular}{c|c|c}
\hline OAE & Estabilidade estrutural & Conservação \\
\hline Ponte sobre o Riacho Camandatuba & 1 & 1 \\
Ponte sobre o Riacho Grande & 3 & 3 \\
\hline
\end{tabular}




\section{CONSIDERAÇÕES FINAIS}

As manifestações patológicas e deficiências funcionais sejam estas oriundas de erros de projeto ou de execução, seleção indevida de materiais de construção, agressividade do meio, cargas excessivas e erosões, foram causas diretas para as insuficiências estruturais apresentadas por ambas as obras em estudo.

No que diz respeito às manifestações patológicas observadas na Ponte sobre o Riacho Grande, pode-se dizer que são decorrentes principalmente da inexistência de pingadeira na laje, dispositivos de drenagem danificados, presença da junta longitudinal na estrutura e falhas de projeto ou execução, tornando os elementos da obra estruturalmente insuficientes.

A Ponte sobre o Riacho Camandatuba também apresenta patologias oriundas da inexistência de pingadeira na laje, de dispositivos de drenagem danificados e falhas de projeto e execução. No entanto, a manifestação patológica mais acentuada ocorre nos pilares da estrutura, devido principalmente à agressividade do meio em que está inserida, tornando as condições de estabilidade da obra precária.

Tais manifestações patológicas afetam as estruturas drasticamente, e, quando não se dispõem de um programa de inspeção e manutenção, as patologias podem-se agravar ainda mais. Portanto, diante dos problemas patológicos, deficiências funcionais e insuficiências estruturais apresentadas no presente estudo e, visando evitar preventivamente tais anomalias nas estruturas em geral, é essencial adotar certos procedimentos, como projetos elaborados de acordo com as normas vigentes, boa qualidade e fiscalização da execução, seleção adequada de materiais de construção, bem como realização de inspeções periódicas para acompanhamento de eventuais patologias e intervenções necessárias, a fim de garantir a segurança estrutural e funcional das obras de artes especiais.

\section{REFERÊNCIAS}

ASSOCIAÇÃO BRASILEIRA DE NORMAS TÉCNICAS. NBR 6118: Projeto de estruturas de concreto procedimento. Rio de janeiro, 2017.

BRASIL. Departamento Nacional de Infraestrutura de Transportes. Diretoria de Planejamento e Pesquisa. Coordenação do Instituto de Pesquisas Rodoviárias. Manual de inspeção de pontes rodoviárias. 2. ed. Rio de Janeiro, 2004. (IPR. Publ., 709).

DEPARTAMENTO NACIONAL DE ESTRADAS DE RODAGEM. Manual de Inspeção de Obras-de-Arte Especiais. Rio de Janeiro, 2004.

DEPARTAMENTO NACIONAL DE ESTRADAS DE RODAGEM - DNER. Manual de projeto Geométrico de Rodovias Rurais. Rio de Janeiro, 1999

DEPARTAMENTO NACIONAL DE INFRAESTRUTURA DE TRANSPORTES. DNIT 088/2006 - ES: Dispositivos de segurança lateral: guarda rodas, guarda corpos e barreiras - Especificação de Serviço. Rio de Janeiro, 2006.

DEPARTAMENTO NACIONAL DE INFRAESTRUTURA DE TRANSPORTE. Inspeções em pontes e viadutos de concreto armado e protendido - Procedimento. NORMA DNIT 010/2004 - PRO. Rio de Janeiro, 2004.

NBR 9452: inspeção de pontes, viadutos e passarelas de concreto - procedimento. Rio de Janeiro, 2016.

SILVA, Nathália Pinheiro da. Sistemas de proteção de pilares de pontes contra colisão de embarcações: Análise e verificação de dois sistemas. 2016. p. 105. Trabalho de Conclusão de Curso em Engenharia Civil e ambiental. Universidade de Brasília, Brasília, DF, 2016.

VITÓRIO, J. A. P. Vistorias, Conservação e Gestão de Pontes e Viadutos de Concreto. Rio de Janeiro, 2006. Trabalho apresentado durante $48^{\circ}$ Congresso Brasileiro do Concreto - CBC2006. 